\title{
Sensitive Determination of Cetirizine Using CdS Quantum dots as Oxidase Mimic-mediated Chemiluminescence of Sulfite
}

\author{
Reza Hoseinpour Kouhestany, *Seyed Naser Azizi, Parmis Shakeri and Shaghyegh Rahmani \\ Faculty of Chemistry, University of Mazandaran, P.O. Box 47416-95447, Babolsar, Iran
}

\begin{abstract}
A new chemiluminescence (CL) method using cadmium sulfide quantum dots (QDs) as sensitizers is proposed for the chemiluminometric determination of cetirizine pharmaceutical formulation. CdS QDs were synthesized by using water soluble route. The nanoparticles were structurally and optically characterized by X-ray diffraction (XRD), Fourier transform infrared spectroscopy (FTIR), Ultra Violet-Visible (UV-Vis) absorption spectroscopy and scanning electron microscopy (SEM). In this study results shows that CdS quantum dots are enhancers of the weak CL emission. Trace amounts of cetirizine improved the sensitize effect of CdS quantum dots yielding a significant chemiluminescence enhancement of the $\mathrm{Ce}(\mathrm{IV})-\mathrm{SO}_{3}{ }^{2-}-\mathrm{CdS}$ QDs system. So, a new CL analysis system was selected for the determination of cetirizine. There is a good linear relationship between the relative chemiluminescence intensity and the concentration of cetirizine in the range of $1 \times 10^{-9}-1 \times 10^{-6} \mathrm{molL}^{-1}$ with a correlation coefficient $\left(\mathrm{R}^{2}\right)$ of 0.9963 at the optimum conditions. The limit of detection (LOD) of this system was found to be $5 \times 10^{-11} \mathrm{M}$. This method is simple, sensitive and cost effective, and also is accommodating for pharmaceutical applications.
\end{abstract}

Key Words: CdS quantum dot, Sensitized chemiluminescence, Ce(IV)-sulfite, Cetirizine.

\section{INTRODUCTION}

Cetirizine (figure 1) is a long acting antihistamine with some mast-cell stabilizing activity widely used in the comprehensive management of allergic rhinitis, the symptoms of which include itching, sneezing and nasal congestion (Haghighi et al., 2013). Its molecular formula is $\mathrm{C}_{21} \mathrm{H}_{2} \mathrm{C}_{13} \mathrm{~N}_{2} \mathrm{O}_{3}$. Cetirizine is an H1-receptor antagonist in a group of the cyclizine class of compounds. It is an active metabolite of hydroxyzine, a first generation H1receptor antagonist. Marked affinity of cetirizine for peripheral histamine $\mathrm{H} 1$ receptors results in anti-allergic properties, but has the advantage that it lacks the CNS depressant effects often encountered in anti-histamines. Cetirizine is a potent and well tolerated nonsedating antihistamine drug for the treatment of seasonal and prennial allergic rhinitis and chronic urticarial (Slater et al., 1999).

In recent years, semiconductor nanocrystals, known as quantum dots (QDs), are in high-demand as inorganic fluorophores (Medintz et al., 2005). Luminescent properties of semiconductor nanocrystals are usually inspected by photoluminescence (PL) produced using photoexcitation (Qu and Peng, 2002), electrochemiluminescence (ECL) generated by electron injection (Zou and $\mathrm{Ju}, 2004)$ and cathodoluminescence given from electron impact (Dabbousi et al., 1997). In recent years, CL and relatedanalysis techniques have been utilized in different fields such as biology, bioimaging, biotechnology and analytical technology because of their widespread liner range, simple instrument and lack of background scattering light interference (Roda et al., 2004). Several advantages, including flexible photoexcitation, sharp photoemission, and excellent resistance to photobleaching have made them more attractive than conventional

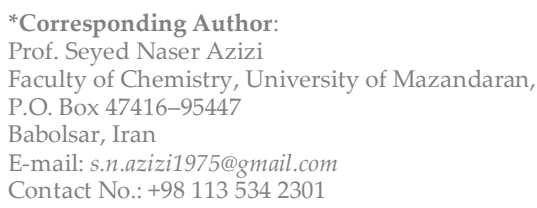

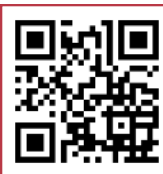

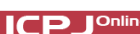

organic fluorophores as luminescent molecular probes (Parak et al., 2005). Thus, fluorescence or chemiluminescence (CL) based chemical sensing involving QDs have been developed for different chemical species such as ascorbic acid, urea, sulfadiazine (Yazid et al., 2013), as well as a ions, such as fluoride, chloride and acetate ions (Callan et al., 2008). In most QDs applications, the detection is based on signal quenching, while more newly attention has been focused on signal enhancing, mainly related to QD ability to sensitize different chemiluminescent systems (Sun et al., 2008). Sensitized chemiluminescence is an expeditious policy to exploit CL reactions with low quantum efficiencies for analytical purposes. The weak created energy is transferred to a sensitizer, usually an organic fluorophore with high quantum yield, which is able to magnify it. Any species that selectively interacts with the fluorophore could quench the CL emission. To our knowledge, up to know, there is no report on sensitize effect of CdS QDs on distinct chemiluminescent systems. In the present study, we have found that the oxidation of sulfite by $\mathrm{Ce}(\mathrm{IV})$ and in the presence of CdS QDs that act as sensitizers produces strong CL signal to allow the development of detection systems. This paper presents a rapid, simple and sensitive method for determination of cetirizine in pharmaceutical formulation.<smiles>O=C(O)COCCN1CCN(C(c2ccccc2)c2ccc(Cl)cc2)CC1</smiles>

Figure1: Structural formula of cetirizine. 


\section{MATERIALS AND METHODS}

\section{Reagents and chemicals}

All the reagents or solvents were of analytical grade and used without further purification. Ultrapure water (deionized and doubly distilled) was used throughout. $\mathrm{Na}_{2} \mathrm{SO}_{3}$, Cadmium chloride hydrate, sodium hydroxide and $\mathrm{H}_{2} \mathrm{SO}_{4}$ were purchased from Merck (Darmstadt, Germany). $\mathrm{Na}_{2} \mathrm{~S} .9 \mathrm{H}_{2} \mathrm{O}$ was from Acros (Geel, Belgium). Cetirizine $(99 \%)$ and $\mathrm{Ce}\left(\mathrm{SO}_{4}\right)_{2} .4 \mathrm{H}_{2} \mathrm{O}$ were purchased from Sigma-Aldrich. The $1 \times 10^{-3} \mathrm{molL}^{-1}$ stock solution of cetirizine was prepared in methanol and the working standard solutions were prepared by diluting stock solution with $\mathrm{H}_{2} \mathrm{O}$ to an appropriate volume.

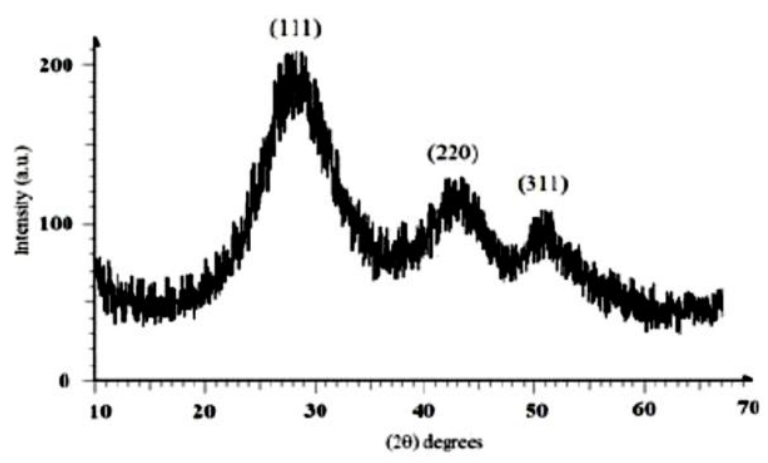

Figure 2: XRD pattern of the CdS nanoparticles.

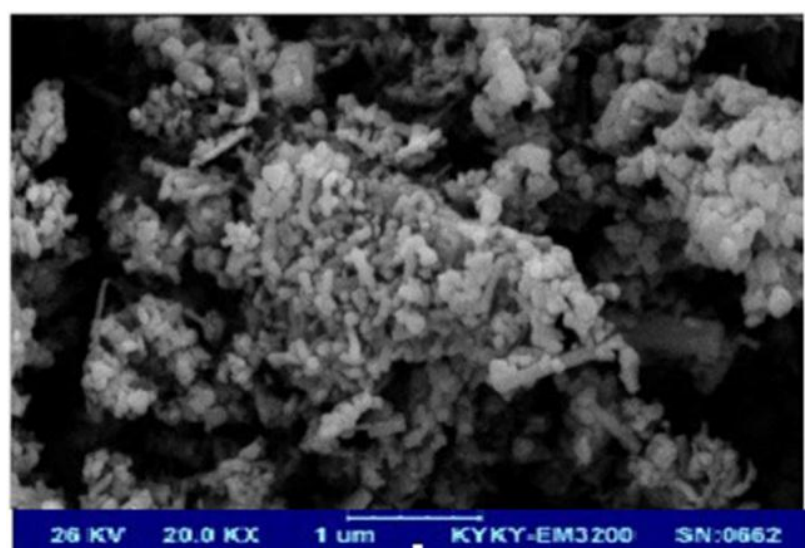

Figure 3: SEM image of CdS nanoparticles.

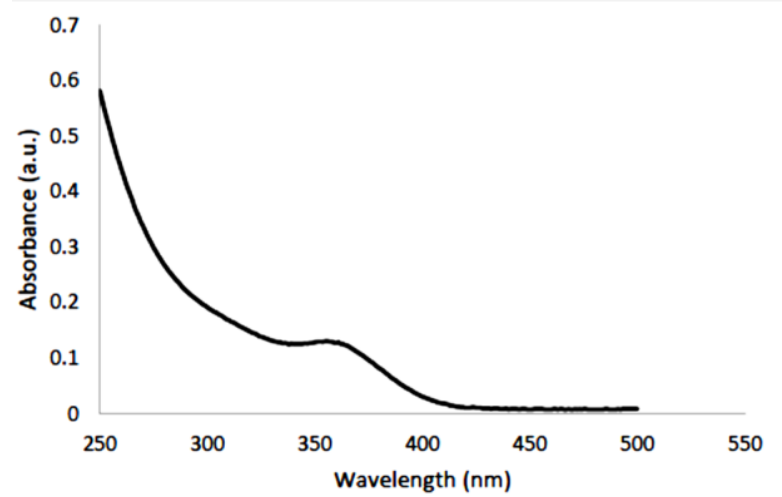

Figure 4: UV-Visible absorption spectra for CdS nanoparticles.

\section{Apparatus}

X-ray diffraction (XRD) patterns were recorded on a Bruker AXS D8 Advance X-ray diffractometer (Bruker, Germany) with $\mathrm{Cu} \mathrm{K} \alpha$ radiation $(\lambda=1.5418 \AA)$. Size of CdS QDs was performed on scanning electron microscope (SEM). The FT-IR spectra $\left(4000-400 \mathrm{~cm}^{-1}\right)$ were recorded using an FT-IR spectrometer (Tensor 27-Bruker). UV- Vis absorbance spectra of CdS nanocrystals were obtained from CdS QDs dispersive solutions using a UV-Vis spectrophotometer (Cambridge, UK). Photoluminescence (PL) measurements were recorded on a Perkin-ElmerL S3B Luminescence Spectrometer (Waltham, USA) using 10 $\mathrm{mm}$ quartz cuvettes. All optical measurements were carried out at room temperature.

Preparation of TGA-Capped CdS QDs nanoparticles Thioglycolic acid (TGA)-stabilized CdS QDs were synthesized via arrested precipitation in water as described previously. Nano crystals were prepared from a stirred solution of $\mathrm{CdCl}_{2}(5 \mathrm{mM})$ in $100 \mathrm{~mL}$ of pure water. The $\mathrm{pH}$ was lowered to $2.15-2.30$ with thioglycolic acid and by dropwise addition of $10 \mathrm{M} \mathrm{NaOH}$ to $\mathrm{pH} 4.5$, followed by further dropwise addition of $1 \mathrm{M} \mathrm{NaOH}$ to obtain a final desired $\mathrm{pH}$ of $7.0 \pm 0.05$. The solution was stirred vigorously under nitrogen atmosphere for $30 \mathrm{~min}$. Then, $20 \mathrm{~mL}$ of $12 \mathrm{mM} \mathrm{Na} 2 \mathrm{~S} .9 \mathrm{H}_{2} \mathrm{O}$ aqueous solution was added to this solution with rapid stirring, in order to set the molar ratio of $\mathrm{Cd}^{2+} / \mathrm{S}^{2-}$ to 1 : 0.4 . The reaction mixture was stirred for $4 \mathrm{~h}$ prior to analysis. Particles were obtained by either the $\mathrm{pH}$ before adding the $\mathrm{Na}_{2} \mathrm{~S} \cdot 9 \mathrm{H}_{2} \mathrm{O}$ solution or the $\left[\mathrm{CdCl}_{2}\right]$ : $\left[\mathrm{Na}_{2} \mathrm{~S}\right]$ molar ratio. The final concentration of the CdS QDs was approximately $4 \times 10^{-3} \mathrm{molL}^{-1}$ (according to the $\mathrm{Cd}^{2+}$ concentration). For purification of CdS QDs, the colloid was dialyzed with $0.01 \mathrm{M} \mathrm{NaOH}$ solution for 2 days. A membrane with a molecular weight of cutoff 7000 was used for the purification of CdS QDs (Chen et al., 2000).

\section{Procedure for CL detection}

Solution A was made by mixing $100 \mu \mathrm{L}$ of CdS QDs (appropriate concentrations in water), $100 \mu \mathrm{L}$ of sulfite and $50 \mu \mathrm{L}$ water or $50 \mu \mathrm{L}$ cetirizine (various concentrations in water). Solution A was delivered to the instruinstrument quartz cuvette via polypropene syringes. The mixture was shaken thoroughly and equilibrated at room temperature for $10 \mathrm{~min}$. Then $50 \mu \mathrm{L}$ proper concentration of $\mathrm{Ce}(\mathrm{IV})$ solution was injected in to the quartz cuvette and the chemiluminescence spectrum was recorded.

\section{RESULTS AND DISCUSSION}

\section{Characterization of CdS QDs}

XRD pattern of the CdS nanoparticles illustrated in Figure 2 can be indexed as hexagonal wurtzite structure of CdS with prominent peaks corresponding to the reflections at (111), (220) and (311) planes. The broadened peaks are showing that the sizes of the particles are in nanorange (Suryanarayana and Norton, 1998).

Figure 3 represents the SEM image of CdS nanoparticles. This picture confirms the formation of $\mathrm{CdS}$ nanoparticles. This picture shows the spherical shape to the nanoparticles, and most of the particles exhibit some covering. From the pictures, it also can be seen that the size of the nanoparticle is less than $50 \mathrm{~nm}$ which was in agreement with the particle sizes $(16.21 \mathrm{~nm})$ calculated from the Debye-Scherrer formula.

The UV-Visible absorption spectra of CdS nanoparticles are shown in Figure 4. Although the wavelength of 


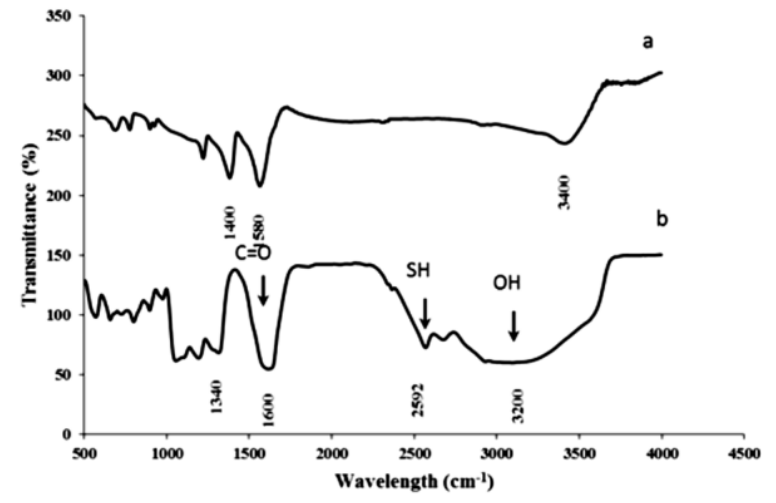

Figure 5: the FT-IR spectra of TGA capped (a) and free TGA (b) CdS nanoparticles.

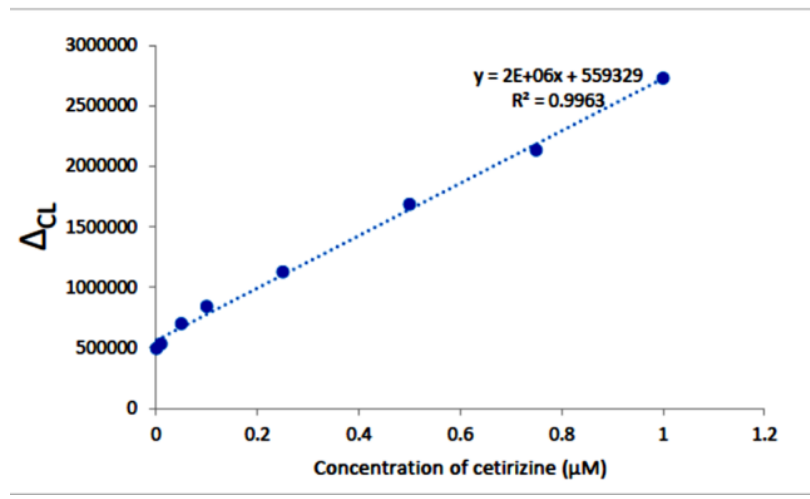

Figure 7: The linear dependence of relative chemiluminescence intensity $\triangle \mathrm{ICL}$ as a function of cetirizine concentration $(\mu \mathrm{mol}$ $\mathrm{L}^{-1}$ ).

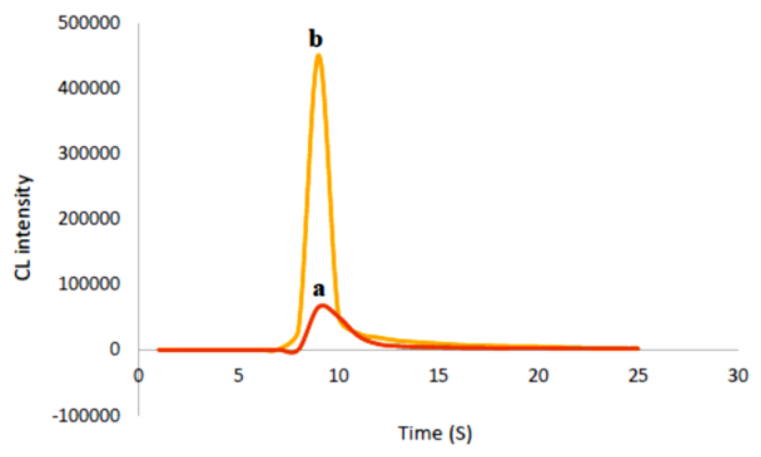

Figure 6: CL intensity-time profiles of $\mathrm{Ce}(\mathrm{IV})-\mathrm{SO}_{3}{ }^{2-}$ (a), $\mathrm{Ce}(\mathrm{IV})-\mathrm{SO}_{3}{ }^{2-} \mathrm{CdS}$ QDs (b).

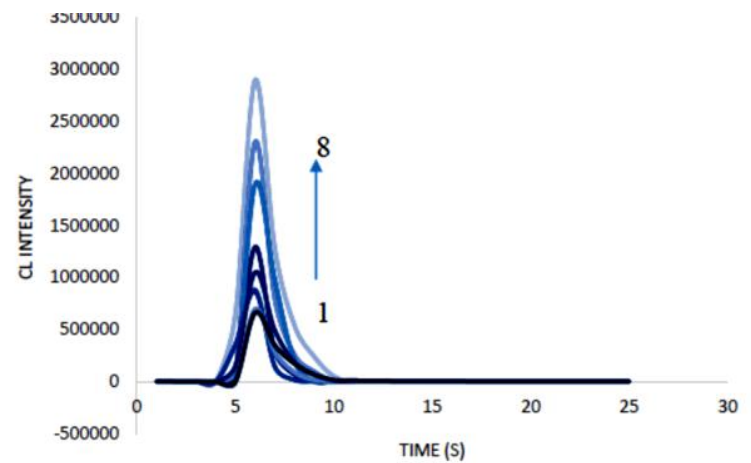

Figure 8: The changes of the CL spectra of $\mathrm{Ce}(\mathrm{IV})-\mathrm{SO}_{3}{ }^{2-}-\mathrm{CdS}$ QDs system after addition of various concentrations of cetirizine. The solution conditions were: $50 \mu \mathrm{L} 5 \times 10^{-4} \mathrm{M} \mathrm{Ce}(\mathrm{IV})$ was injected into a mixture of $100 \mu \mathrm{L} 1.0 \times 10^{-3} \mathrm{M} \mathrm{SO}_{3}^{-2}$ plus 100 $\mu \mathrm{L} 1 \mathrm{M}$ CdS QDs solution with different concentrations of cetirizine: (1) $0.001,(2) 0.01,(3) 0.05$, (4) $0.1,(5) 0.25,(6) 0.5,(7)$ 0.75 , and (8) $1 \mu \mathrm{mol} \mathrm{L}^{-1}$.

Table 1: Determination of cetirizine in pharmaceutical sample by the proposed method.

\begin{tabular}{ccccc}
\hline Formulation & $\begin{array}{c}\text { Claimed value } \\
(\mathbf{m g} / \mathbf{m l})\end{array}$ & $\begin{array}{c}\text { Found } \\
(\mathbf{m g} / \mathbf{m l})\end{array}$ & Recovery (\%) & RSD (\%) (n=3) \\
\hline $\begin{array}{c}\text { Cetirizine injection } \\
(10 \mathrm{mg} / \mathrm{ml})\end{array}$ & 10 & 0.96 & 97.5 & 2.5 \\
\hline
\end{tabular}

Table 2: Results of determination and recoveries in pharmaceutical formulation.

\begin{tabular}{ccccc}
\hline Sample & Added $\left(\mathbf{1 0}^{-\mathbf{7}}\right)$ & Observed $\left(\mathbf{1 0}^{-\mathbf{7}}\right)$ & Recovery $\mathbf{( \% )}$ & RSD (\%) $(\mathbf{n}=\mathbf{3})$ \\
\hline 1 & 1 & 0.97 & 96.6 & 3.2 \\
2 & 5 & 5.85 & 101 & 2.5 \\
3 & 10 & 10.4 & 103 & 2.8 \\
\hline
\end{tabular}


our spectrometer is omitted by the light source, the absorption band of the CdS nanoparticles shows a blue shift due to the quantum confinement of the excitations present in the sample as compared with the bulk CdS particles. This optical phenomenon shows that these nanoparticles have a quantum size effect (Azizi et al., 2013; Berger, 1996 ).

In addition, Fourier transform infrared spectroscopy was carried out in order to confirm the bonding of thioglycolic acid (TGA) to the nanoparticle surface. Figure 5 shows the FT-IR spectra of TGA capped (a) and free TGA (b) CdS nanoparticles. The IR absorption band around 1550-1610 cm-1, 1300- $1450 \mathrm{~cm}^{-1}$ (sv COO-), 3000$3500 \mathrm{~cm}^{-1}(\mathrm{mv} \mathrm{OH})$ and $2550-2750 \mathrm{~cm}^{-1}$ (sv S-H) indicate these groups. Results showed that the stretching band of the $\mathrm{S}-\mathrm{H}$ thiol group, $\left(2550-2670 \mathrm{~cm}^{-1}\right.$ wo $\left.\mathrm{S}-\mathrm{H}\right)$, is not observed when the nanoparticles are evaluated. The reason for disappearance of $\mathrm{S}-\mathrm{H}$ group vibration on the surface of CdS nanoparticles is due to the formation of covalent bonds between thiols and $\mathrm{Cd}^{2+}$ surface atoms (Wang et al., 2011).

\section{Chemiluminescence of CdS QDs}

Chemiluminescence emission of CdS ODs was studied in $\mathrm{Ce}(\mathrm{IV})-\mathrm{SO}_{3}{ }^{2-}-\mathrm{CdS}$ QDs system. It was reported that the oxidation of sulfite by $\mathrm{Ce}^{4+}$ in acidic medium yields a weak chemiluminescent emission, which can be enhanced in the presence of sensitizers or fluorophore compounds, one of which is QDs that attract special attention due to their high quantum yields (Wang et al., 2009; Fortes et al., 2011). Therefore, in this study we study the effects of CdS $\mathrm{NCs}$ on the $\mathrm{Ce}(\mathrm{IV})-\mathrm{SO}_{3}{ }^{2-} \mathrm{CL}$ system. Figure 6 shows the dynamic CL intensity-time profiles of the $\mathrm{Ce}$ (IV)- $\mathrm{SO}_{3}{ }^{2-}$ (curve a) and $\mathrm{Ce}(\mathrm{IV})-\mathrm{SO}_{3}{ }^{2-}-\mathrm{CdS}$ QDs (curve b) were acquired in the static-injection mode. It indicated (Figure $6 \mathrm{~b})$ that the $\mathrm{CL}$ reaction was very quick and the CL intensity reached a maximum in about a second after the injection. It could be seen from Figure 6 that the CL intensity of $\mathrm{Ce}(\mathrm{IV})-\mathrm{SO}_{3}{ }^{2-}-\mathrm{CdS} \mathrm{NCs}$ (nanocrystallites) system is far stronger than that of $\mathrm{Ce}$ (IV) $-\mathrm{SO}_{3}{ }^{2-}$ system, indicating the great sensitized effect of CdS NCs on Ce (IV) $-\mathrm{SO}_{3}{ }^{2-} \mathrm{CL}$ reaction. Useful arameters for the $\mathrm{CL}$ signals of $\mathrm{Ce}(\mathrm{IV})-\mathrm{SO}_{3}{ }^{2-}-\mathrm{CdS} \mathrm{NCs}$ system were then investigated systematically to establish the optimal conditions for the CL reaction. This optimization was carried out in the following experiment.

\section{Calibration curves and performance characteristics}

By adding different amounts of cetirizine proposed system (Ce(IV)- $\mathrm{SO}_{3}{ }^{2-} \mathrm{CdS}$ QDs) changes in chemiluminescence intensities $\left(\Delta \mathrm{I}_{\mathrm{CL}}\right)$ are quantitatively related to the concentration of cetirizine. Under the optimal experimental conditions described above, the calibration graph (i.e., the relationship between the concentration of cetirizine and the changes in the intensities) was shown (Figure 7) and following results were: the regression equation is $\Delta \mathrm{I}_{\mathrm{CL}}=2 \mathrm{E}+06 \mathrm{C}+559329$ (where $\mathrm{C}$ is the concentration of cetirizine, in $\mu \mathrm{molL}^{-1}$ ) with correlation coefficient $\left(\mathrm{R}^{2}\right)$ of 0.9963 , the linear range is $1 \times 10^{-9}-1 \times 10^{-6}$ $\mathrm{molL}^{-1}$ and the detection limit $(\mathrm{S} / \mathrm{N}=3)$ is $5 \times 10^{-11} \mathrm{molL}^{-1}$ cetirizine (Figure 8 ). From Table 1, it can be found that the proposed method has a lower detection limit and larger linear range, compared with most of other methods.

\section{Sample determination and recovery tests}

To test the proposed method, it was applied to the analysis of cetirizine in injection. The samples were diluted appropriately with water before measurement. The results are shown in Table 1. As can be seen, the RSD was $2.5 \%$ and the recovery of the real samples was $97.5 \%$, which suggested that there were no significant differences between the compared values, making this new chemiluminescence method applicable to these pharmaceutical formulations. Recovery tests were done to estimate the accuracy of this method. So a specific amount of standards was added to injection sample in three different levels. Results are given in Table 2 . The recoveries ranged from $96.6 \%$ to $103 \%$, with RSDs of $<4 \%$. It shows that the proposed method was appropriate.

\section{CONCLUSION}

In summary, cetirizine inhibits strongly the CL intensity of the Ce (IV)-SO ${ }_{3}{ }^{2-}-\mathrm{CdS}$ QDs system. In fact, a simple and sensitive $\mathrm{CL}$ method for the determination of cetirizine is established, the increase in the CL signal being proportional to the concentration of cetirizine in the range of $5 \times 10^{-9}-1 \times 10^{-6} \mathrm{molL}^{-1}$. Moreover, the analytical results of real samples were accommodating. The proposed method has been applied to the determination of low levels of cetirizine in pharmaceutical products.

\section{REFERENCES}

Azizi, S. N., Chaichi, M. J., Shakeri, P., \& Bekhradnia, A. (2013). Determination of epinephrine in pharmaceutical formulation by an optimized novel luminescence method using CdS quantum dots as sensitizer. Journal of fluorescence, 23(2), 227-235. [DOI

Berger, L. I. (1996). Semiconductor materials. CRC press.

Callan, J. F., Mulrooney, R. C., Kamila, S., \& McCaughan, B. (2008). Anion sensing with luminescent quantum dots-a modular approach based on the photoinduced electron transfer (PET) mechanism. Journal of fluorescence, 18(2), 527-532. [DOI]

Chen, H. M., Huang, X. F., Xu, L., Xu, J., Chen, K. J., \& Feng, D. (2000). Selfassembly and photoluminescence of CdS-mercaptoacetic clusters with internal structures. Superlattices and Microstructures, 27(1), 1-5. [DOI]

Dabbousi, B. O., Rodriguez-Viejo, J., Mikulec, F. V., Heine, J. R., Mattoussi, H., Ober, R., \& Bawendi, M. G. (1997). (CdSe) ZnS core-shell quantum dots: synthesis and characterization of a size series of highly luminescent nanocrystallites. The Journal of Physical Chemistry B, 101(46), 9463-9475. [DOI]

Fortes, P. R., Frigerio, C., Silvestre, C. I., Santos, J. L., Lima, J. L., \& Zagatto, E. A (2011). Cadmium telluride nanocrystals as luminescent sensitizers in flow analysis. Talanta, 84(5), 1314-1317

Haghighi, S., Shapouri, M. R., Amoli-Diva, M., Pourghazi, K., \& Afruzi, H. (2013) HPTLC-densitometric determination of cetirizine and montelukast analysis in combined tablet dosage forms. Iranian Journal of Pharmaceutical Research, 12(2), 303-309.

Medintz, I. L., Uyeda, H. T., Goldman, E. R., \& Mattoussi, H. (2005). Quantum dot bioconjugates for imaging, labelling and sensing. Nature materials, 4(6), 435-446. http://dx.doi.org/ 10.1038/nmat1390

Parak, W. J., Pellegrino, T., \& Plank, C. (2005). Labelling of cells with quantum dots. Nanotechnology, 16(2), R9. [DOI]

Qu, L., \& Peng, X. (2002). Control of photoluminescence properties of CdSe nanocrystals in growth. Journal of the American Chemical Society, 124(9), 20492055. [DOI]

Roda, A., Pasini, P., Mirasoli, M., Michelini, E., \& Guardigli, M. (2004). Biotechnological applications of bioluminescence and chemiluminescence. TRENDS in Biotechnology, 22(6), 295-303. [DOI]

Slater, J. W., Zechnich, A. D., \& Haxby, D. G. (1999). Second-generation antihistamines. Drugs, 57(1), 31-47. [DOI]

Sun, C., Liu, B., \& Li, J. (2008). Sensitized chemiluminescence of CdTe quantumdots on Ce (IV)-sulfite and its analytical applications. Talanta, 75(2), 447-454. [DOI]

Suryanarayana, C., \& Norton, M. G. (1998). X-ray diffraction: a practical approach. Microsc Microanal, 4, 513-5. [DOI]

Wang, Y., Lu, J., Tong, Z., Li, B., \& Zhou, L. (2011). Facile synthesis of CdS nanocrystals using thioglycolic acid as a sulfur source and stabilizer in aqueous solution. Bulletin of the Chemical Society of Ethiopia, 25(3).

Wang, Z., Li, J., Liu, B., \& Li, J. (2009). CdTe nanocrystals sensitized chemiluminescence and the analytical application. Talanta, 77(3), 1050-1056. [DOI]

Yazid, S. N. A. M., Chin, S. F., Pang, S. C., \& Ng, S. M. (2013). Detection of Sn (II) ions via quenching of the fluorescence of carbon nanodots. Microchimica Acta, 180(1-2), 137-143. [DOI]

Zou, G.Z., \& Ju, H.X. (2004). Analytical Chemistry. 76, 6871- 6876 